\title{
El poder estructurante del género, el amor y la sexualidad: Un análisis del espacio simbólico de “Feministlán”
}

\section{The Structuring Power of Gender, Love and Sexuality: An Analysis of the Symbolic Space of "Feministlán”}

Alonso Pi Cholula

Ciudad de México, México, email: acholula@colmex.mx,

(O) https://orcid.org/00oo-0001-8523-0996

Recibido: 4 de agosto

de 2020

Aceptado: 13 de enero

de 2021

Publicado: o1 de

marzo de 2021

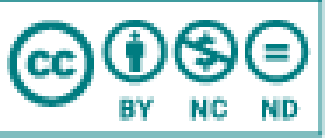

Esta obra está protegida bajo una

Licencia Creative Commons

Atribución-NoComercial-

SinDerivadas 4.0 Internacional (CC

BY-NC-ND 4.0)

\section{Resumen}

El objetivo de este artículo es analizar la relación entre dos elementos: a) las formas de hacer un performance de género en el amor y la sexualidad y b) la organización del espacio simbólico (Feministlán) en el que están situadas distintas activistas feministas. Con base en el método biográfico, se realizaron entrevistas semiestructuradas a 21 mujeres feministas que viven en la Ciudad de México. Se encontró que el amor y la sexualidad tienen un interés público en Feministlán, pues constituyen ámbitos de experiencia en los que se puede demostrar el sentido político asignado a la identidad de género. Además, se

CÓMO CITAR: Pi, Cholula. (2021). El poder estructurante del género, el amor y la sexualidad: Un análisis del espacio simbólico de “Feministlán” Revista Interdisciplinaria de Estudios de Género de El Colegio de México, 7, e693. doi: http://dx.doi.org/10.24201/reg.v7i1.693

\footnotetext{
${ }^{1}$ Este artículo presenta algunos de los resultados más importantes de la investigación de maestría realizada por el autor en el Programa de Estudios de Género de El Colegio de México. La investigación fue dirigida por la doctora Ana Paulina Gutiérrez Martínez y comentada por la doctora Karine Tinat y la doctora Natalia Tenorio Tovar.
} 
concluyó que Feministlán puede conceptualizarse como un "campo", un orden de género y un régimen emocional.

Palabras clave: trabajo emocional; performance de género; mujeres feministas; amor; sexualidad.

\begin{abstract}
This article analyzes the relationship between two elements: a) ways of carrying out a gender performance of love and sexuality, and b) the organizing of a symbolic space (Feministlán) inhabited by different feminist activists. Applying a biographical method with 21 feminist women in Mexico City, it was revealed that love and sexuality are matters of public interest in Feministlán, since they constitute realms of experience in which is possible to demonstrate the political significance attributed to gender identity. Furthermore, it was concluded that Feministlán can be conceptualized as a "field", a gender order, and an emotional regime.
\end{abstract}

Keywords: emotional work; gender performance; feminist women; love; sexuality.

\title{
Introducción
}

La vida amorosa de las mujeres feministas no ha pasado desapercibida en la investigación académica. Algunos estudios señalan cómo la incursión de una mujer en el mundo de los feminismos puede traer cambios en sus formas de elegir pareja (Backus y Mahalik, 2011; Rudman y Phelan, 2007), sus acuerdos amorosos (Hand, 2013; Pinckert, 2012), sus representaciones simbólicas del amor (Esteban, 2009; Esteban y Távora, 2008; García, 2017; Pinckert, 2012) y sus prácticas sexuales (Yoder, Rachel y Ellen, 2007). Estas trasformaciones no siempre son totales, puesto que en los itinerarios amorosos de mujeres feministas pueden verse contradicciones entre sus hábitos románticos de comportamiento y sus intenciones orientadas por principios feministas (Faulkner y Ruby 2015; García, 2017). También hay 
investigaciones que, yendo más allá de lo relativo a la experiencia, se centran en los debates sobre el amor entre distintas corrientes feministas (Payne, 2010).

Tomando una ruta más cercana a la de Payne (2010) que a la del resto de las investigaciones mencionadas, me planteo lo siguiente: si desde los feminismos se está en contra de la reproducción de las desigualdades de género en el amor, ¿qué modelos de relación amorosa promueven? Y, no menos importante, ¿qué clase de feminidad va implícita en esos modelos? Con el objetivo de responder a estas preguntas, en este artículo presento, por un lado, un análisis cualitativo acerca de la relación entre las formas de "hacer género" en el amor y la sexualidad (Butler, 2007), y por el otro, la organización del espacio simbólico que denomino "Feministlán". Para lograrlo, me baso en la reconstrucción de narrativas biográficamente orientadas de distintas mujeres feministas cisgénero y una mujer trans ${ }^{* 2}$. Dichas mujeres tienen distintas edades, afinidades políticas, orientaciones sexuales y capitales, pero todas viven en la Ciudad de México.

Recupero el término "Feministlán" de una entrevista que realicé con Garnet ${ }^{3}$ (43 años) para referirme, como lo hizo ella, a un espacio simbólico de carácter heterogéneo en el que conviven todas las mujeres y agrupaciones feministas. Es imposible determinar los límites de Feministlán, porque su perímetro no concuerda con el de ningún sitio geográfico: se trata, más bien, de un espacio urbano que integra lo ocurrido dentro y fuera de internet. Entiendo Feministlán como un campo, es decir, un sitio cuya organización jerárquica de posiciones responde a la distribución de una determinada forma de "capital" (Bourdieu, 2002). A reserva de explorar más adelante cuál es ese capital, cabe decir que Feministlán es, también, un orden de género y un régimen emocional, en tanto que su organización descansa, al menos en parte, en las formas de poner en acto el sentido político asignado a la identidad de género en las relaciones amorosas y sexuales. Tal organización da cuenta de relaciones de poder asimétricas, las cuales, como en todo campo, a veces son desafiadas y otras más aceptadas.

\footnotetext{
${ }^{2}$ Uso el término trans* con un asterisco para destacar, como lo hacen Alba Pons y Eleonora Garosi, inspirándose en Mauro Cabral (2009), “...la variabilidad y pluralidad de experiencias situadas cultural y políticamente que se pueden enmarcar dentro de lo trans*" (2016, pp. 311-312).

${ }^{3}$ Así como en el caso de Garnet, todos los nombres de las entrevistadas son seudónimos que ellas eligieron o que yo les asigné para proteger sus identidades.
} 
Este artículo se compone de tres apartados. En el primero expongo cómo empleé el método biográfico y las entrevistas semiestructuradas; asimismo, me posiciono como investigador frente a mi objeto de estudio. En el segundo desarrollo el alcance de un conjunto de conceptos, los cuales se encuentran en los terrenos de la Sociología del Conocimiento, la Sociología de las Emociones, la Sociología Disposicional y los Estudios de Género. En el tercero analizo la lógica de Feministlán, en virtud de tres elementos: el género, el amor y la sexualidad.

\section{Estrategia Metodológica}

Realicé 23 entrevistas semiestructuradas a 21 mujeres feministas entre los meses de febrero y agosto de $2019^{4}$. Para la conformación de la muestra de entrevistadas utilicé el procedimiento conocido como "bola de nieve", en el que se eligen participantes a partir de las recomendaciones que hacen las personas bajo estudio. La selección de las entrevistadas fue guiada por los siguientes criterios: 1) que se definieran como mujeres feministas; 2) que hubieran colaborado en agrupaciones feministas con orientaciones políticas diferentes; 3) que tuvieran distintas edades; 4) que pudieran ser ubicadas, en virtud del conjunto de recursos a su alcance, en posiciones diferentes del espacio social. Elegí el primero, pues creí que únicamente podría llegar a tener interlocutoras si tomaba por válida la definición que ellas hacen de sí mismas. La elección del segundo, tercero y cuarto criterio fue para garantizar un espectro más o menos heterogéneo de socialización feminista y de género que me permitiera elaborar comparaciones.

En esta investigación seguí la línea del método biográfico, el cual es ideal para acoplarse a la siguiente recomendación de Bourdieu: conjugar el estudio de "la experiencia de los agentes sociales y el análisis de estructuras objetivas que hacen posible esa experiencia" (2001, p. 80). Tal método considera que una biografía individual da muestras de la particularidad subjetiva de una persona, al tiempo que ofrece notas acerca de cómo esa peculiaridad está atravesada por la cultura de su tiempo. Así, el método biográfico “...parece prometer esa

\footnotetext{
${ }^{4} \mathrm{~A}$ un par de mujeres las entrevisté dos veces, dado que nuestro primer encuentro fue muy corto. Al resto de interlocutoras las entrevisté en una sola ocasión.
} 
mediación del acto a la estructura, de la historia individual a la historia social..." (Rojas, 2013, p. 168). Esto implica que un itinerario de vida y su ambiente social forman una unidad indisoluble: la narración biográfica transformada en texto sólo es inteligible de cara a su contexto social de producción (Ferraroti, 2007).

La técnica que usé para recopilar información fue la entrevista semiestructurada. Aunque el método biográfico está pensado para realizar relatos de vida y no entrevistas semiestructuradas, entre una y otra técnica hay un hilo de continuidad. Según Daniel Bertaux, "hay relato de vida desde el momento en que un sujeto cuenta a otra persona, investigador o no, un episodio cualquiera de su experiencia de vida" (2005, p. 35). Esta definición no contradice la de las entrevistas semiestructuradas que yo realicé: encuentros en los que está presente un "entrevistado que trasmite información, y un entrevistador que la recibe, y entre ellos existe un proceso de intercambio simbólico que retroalimenta este proceso" (Vela, 2013 p. 65). Por otro lado, Bertaux afirma que un relato de vida no tiene una pretensión totalizadora, pues su objetivo no es detectar "todos los significados que pueda contener, sino sólo los pertinentes, los que pueden ayudar al estudio del objeto de investigación..." (2005, p. 74). Esta descripción cabe en el molde de las entrevistas semiestructuradas, en tanto que éstas se proponen crear una situación en la que la persona entrevistada pueda expresar "ciertas partes esenciales sobre sus referencias pasadas y/o presentes, así como sobre sus anticipaciones e intenciones futuras" (Kahn y Cannell, 1997 en Vela, 2013, p. 65). Entonces, la indistinción entre relatos de vida y entrevistas semiestructuradas es lo que me permitió inscribir a las últimas dentro del método biográfico.

El supuesto epistemológico básico de esta investigación es que toda construcción de conocimiento es situada (Bourdieu, 2003). Esto quiere decir que un análisis, al margen de su temática, es hecho en función de un punto de vista particular, el cual adquiere su forma a partir de los intereses, conocimientos, experiencias y ubicación en determinadas coordenadas sociales de una persona cognoscente. Hacer explícito lo anterior, a decir de Norma Blázquez (2010), es un requisito indispensable para alcanzar lo que Sandra Harding (1998) denomina “objetividad fuerte", o sea, aquella postura en la que se enuncian, desde el inicio, las posibles fuentes de sesgo en una investigación. 
La lista de elementos que componen mi punto de vista podría ser interminable: la clase social en la que fui socializado, mi nivel de escolaridad, la raza que me fue asignada en virtud de mi color de piel, entre otros. Cada uno de esos elementos me coloca en distintas posiciones de privilegio o subalternidad frente a cada una de las entrevistadas. Sin embargo, en tanto que soy hombre, acumulo una serie de privilegios que me han llevado a tener un itinerario de vida distinto al de las entrevistadas. En algún momento consideré que esta diferencia sería un obstáculo infranqueable, pues imaginé que me haría propenso a pasar por alto elementos importantes de sus narraciones y a preguntar desde la ignorancia acerca de temas que para ellas podrían resultar incómodos.

Una vez en el campo, mis miedos se revelaron como "tigres de papel": amenazas reales, pero de una dimensión bastante menor a la que yo había imaginado. Probablemente porque soy un hombre heterosexual, las entrevistadas no abundaron en cuestiones relativas a sus cuerpos $^{5}$. No obstante, me atrevería a decir que la mayoría de las entrevistas estuvo atravesada por el entusiasmo: yo tenía ganas de escuchar, ellas tenían ganas de hablar. Me parece que esto se debió a que las entrevistas además de ser el escenario para la verbalización de sus experiencias también fueron la oportunidad para que ellas pudieran poner en acto, sin la amenaza de un cuestionamiento, su identidad política. A fin de cuentas, yo, un hombre que no forma parte de las agrupaciones feministas, no constituí una figura de autoridad ante la que ellas buscaran causar una buena impresión. En todo caso, adopté el papel de un ingenuo cuyas preguntas estaban guiadas por la curiosidad y no por la mala fe.

\section{Abordaje teórico Campo, capital y habitus}

Para Bourdieu, el "capital es trabajo acumulado, bien en forma de materia, bien en forma interiorizada o incorporada" (2001, p. 131). Esto tiene, por lo menos, dos implicaciones, la primera, que la acumulación de capital tiene una historia y, por lo tanto, "requiere tiempo"

\footnotetext{
${ }^{5}$ Cabe mencionar que esta investigación fue originalmente realizada para dar cuenta de la mutua influencia entre experiencias amorosas y procesos de socialización y politización feminista.
} 
(2001, p. 132); la segunda, que el capital está inscrito "en la objetividad de las cosas" y en los cuerpos de quienes lo detentan (2001, p. 132). Asimismo, según Bourdieu, las distintas formas en las que se presenta el capital pueden intercambiarse entre sí; esta trasmutación no siempre es inmediata, por cuanto implica, como condición, la aplicación de esfuerzo o trabajo.

Dice Bourdieu que el capital "puede presentarse de tres maneras fundamentales" (2001, p. 135). El capital económico "es directa o inmediatamente convertible en dinero, y resulta especialmente indicado para la institucionalización en forma de derechos de propiedad" (2001, p. 135). El capital cultural se puede presentar de tres maneras diferentes: de manera interiorizada "en forma de disposiciones duraderas del organismo"; de manera objetivada "en forma de bienes culturales" y de manera institucionalizada que "confiere propiedades enteramente originales al capital cultural que debe garantizar" y que se puede ver, por ejemplo, en títulos académicos (2001, pp. 135-136). El capital social consiste en "la totalidad de los recursos potenciales o actuales asociados a la posesión de una red duradera de relaciones más o menos institucionalizadas de conocimiento y de reconocimiento mutuos" (2001, p. 148). Cabe añadir otra forma de capital: el simbólico. A pesar de llamarse "capital", no es, en estricto sentido, una forma de éste. Se trata, más bien, de "la forma que adoptan los diferentes tipos de capital una vez que son percibidos y reconocidos como legítimos" (Bourdieu, 2001, p. 106). Por eso, esta forma inviste de reconocimiento público a la persona que lo detenta, ya que hace que sus conocimientos o autoridad se vean, a ojos de las otras personas, como propiedades válidas (Bourdieu, 2001).

Los campos, entendidos como "espacios estructurados de posiciones" relacionadas entre sí (Bourdieu, 2002, p. 119), son estructurados en virtud de su distribución interna de capital específico. Por eso, la "estructura de distribución de los diferentes tipos y subtipos de capital, dada en un momento determinado del tiempo, corresponde a la estructura inmanente del mundo social" (Bourdieu, 2001, p. 132). La lógica de los campos consiste en la lucha, ésta supone el mutuo acuerdo, aunque sea tácito, entre quienes ocupan las distintas posiciones respecto al elemento que está en juego y por el cual compiten, es decir, el capital específico del campo en el que se encuentran. Para el funcionamiento de la lógica de los campos es 
importante que quienes ocupan las posiciones posean "los habitus que implican el conocimiento y reconocimiento de las leyes inmanentes al juego, de lo que está en juego, etcétera" (Bourdieu, 2002, p. 120).

El habitus es el producto de la incorporación de disposiciones heterogéneas, e incluso contradictorias, que se logra a través de las múltiples socializaciones que una persona atraviesa a lo largo de su vida. Esto implica que una persona puede ser, por así decirlo, dos personas distintas en dos momentos o espacios que estén anclados a redes sociales diferentes. En ese sentido, el habitus no es un conjunto de esquemas de acción monolítico que se lleva de una situación a otra, una "fórmula mágica generadora de todas nuestras prácticas" (Lahire, 2004, p. 70), como un conjunto de esquemas incorporados ("esquemas sensomotrices, esquemas de percepción, apreciación, evaluación...” [Lahire, 2004, p. 47]) que se movilizan dependiendo de la situación.

\section{Emociones}

Oliva López propone la categoría de "dispositivos emocionales" para referirse a "estrategias discursivas e institucionales que (...) contribuyen a generar un determinado capital emocional en relación con los sexos, las clases sociales, la edad y la profesión” (2011, p. 51). Los dispositivos son incorporados por medio de procesos de socialización y funcionan como disposiciones de autocontención emocional. Los dispositivos emocionales encuentran su origen en los "regímenes emocionales" (López, 2013); éstos últimos son un grupo de normas acerca de las formas legítimas de sentir y expresar lo sentido. La reproducción de los regímenes emocionales descansa sobre la incorporación de dispositivos emocionales, dado que ésta conduce a que la experiencia y la expresión emocionales de las personas se ajusten y den continuidad a las normas del sentir que se encuentran en los regímenes mismos.

Por su parte, Arlie Hochschild (1979) se enfoca en estudiar los esfuerzos volitivos para manejar las emociones. Tal manejo o "trabajo emocional” puede ser de evocación (hacerse sentir lo que no se siente) o de supresión (reprimir lo que se siente) (Hochschild, 1979). Ambas formas de trabajo emocional suponen una dirección: de una persona hacia sí misma. 
En este caso, el trabajo emocional suele hacerse cuando el sentir individual no se corresponde con las convenciones del sentir de un contexto específico. Para cerrar la brecha entre la situación y el sentir, dice Hochschild, las personas pueden echar mano de distintas estrategias de trabajo emocional, por ejemplo: cognitivo, corporal y expresivo ${ }^{6}$.

Hochschild plantea que las formas de sentir están orientadas por "reglas del sentir", las cuales son patrones compartidos socialmente que, la mayoría de las veces, permanecen latentes. Esto significa que no necesariamente pertenecen a la dimensión consciente de la cognición, en tanto que han sido incorporadas como disposiciones que operan de forma más o menos inmediata (Hochschild, 1979). Se puede llegar a las reglas del sentir por dos caminos, por un lado, atendiendo los reclamos sobre una persona que no está sintiendo de la forma en la que debería, según las convenciones de la situación en la que se encuentra; en este caso, tenemos una afrenta que subraya la existencia y contenido de una regla. Por otro lado, prestando atención a los esfuerzos por reducir la distancia de la "disonancia emocional", es decir, la distancia existente entre las reglas del sentir que marca una situación/interacción y lo sentido.

\section{Género}

Para Joan Wallach Scott: "el género es un elemento constitutivo de las relaciones sociales, las cuales se basan en las diferencias percibidas entre los sexos, y el género es una forma primaria de las relaciones simbólicas de poder" (2008, p. 65). Respecto a la primera parte de la definición, Scott señala que el género se compone de cuatro elementos interrelacionados: representaciones simbólicas, conceptos normativos, instituciones y organizaciones sociales e identidad subjetiva. En la segunda parte de la definición, la historiadora afirma que “...el género es un campo primario dentro del cual, o por medio del cual, se articula el poder" (Scott, 2008, p. 68). En ese sentido, el género puede ser utilizado como un criterio a partir del cual se lleva a cabo una distribución de personas en posiciones de mayor o menor

\footnotetext{
${ }^{6}$ La estrategia cognitiva es el "intento de cambiar imágenes, ideas o pensamientos en pos de modificar los sentimientos asociados con ellos"; la estrategia corporal es "el intento de cambiar síntomas somáticos o físicos de las emociones" como respirar más lento; la estrategia expresiva descansa en el intento "de cambiar gestos expresivos en pos de cambiar los sentimientos internos" como intentar sonreír para no estar triste (Hochschild, 1979, p. 562).
} 
jerarquía. Este ejercicio casi siempre culmina en la estructuración de un espacio social en el que prima, entre hombres y mujeres, un diferencial de poder que permite a los primeros sacar ventajas a costa de las segundas. Sin embargo, el poder no solamente se articula en relaciones entre géneros, sino también dentro de un mismo género.

Por otro lado, el género puede ser entendido como un performance, esto implica no considerar el género como una posesión o una esencia, sino como algo que se hace a través de conductas situadas en interacción con otras personas (West y Zimmerman, 1987). Así, el género consiste en una producción cotidiana, cuya manifestación depende del conjunto de relaciones que se dan en un contexto social determinado. Tal producción es la puesta en acto de normas que "nos preceden y que nos exceden" (Butler, 2009, p. 333), es decir, que no dependen de las personas que las realizan en su actuar. De hecho, no sabemos "qué es exactamente lo que las normas de género esperan de nosotros, y sin embargo nos encontramos motivados y orientados dentro de sus términos" (Butler, 2009, p. 333).

\section{Socialización}

La socialización puede ser vista como el proceso intersubjetivo a través del cual una persona se convierte en "miembro de la sociedad" (Berger y Luckmann, 2012, p. 164). Dicho proceso descansa sobre la administración de conocimiento, el cual, en contextos de gran diferenciación social como la Ciudad de México, no está distribuido de manera homogénea. Esto da lugar a la existencia de distintos stocks de conocimiento que favorecen la emergencia de socializaciones diferentes. No obstante, lo que está en juego en cualquier tipo de socialización es la "mediatización" de una definición de la realidad para que las personas la utilicen como un referente para interpretar y actuar en la vida cotidiana (Berger y Luckmann, 2012).

La mediatización de conocimiento es llevada a cabo por un "elenco de socialización" (Berger y Luckmann, 2012). Tal mediatización, en tanto que corresponde al punto de vista de un elenco particular, siempre es parcial. El contacto con múltiples elencos de socialización desemboca en la construcción de un "sujeto plural": aquella persona que ha sido socializada, 
“...simultánea o sucesivamente, en el seno de una pluralidad de mundos sociales no homogéneos, y a veces incluso contradictorios, o en el seno de universos sociales relativamente coherentes, pero que presentan contradicciones en algunos aspectos..." (Lahire, 2004, p. 47).

\section{Feministlán}

\section{La lógica del campo}

Al interior de Feministlán conviven personas con identidades políticas diferentes que, a pesar de compartir el objetivo de eliminar el peso que la dominación masculina ha puesto sobre ellas, pueden enfrascarse en arduas dinámicas de crítica. Algunas entrevistadas que se identifican con el feminismo socialista me señalaron, respecto al feminismo radical, que "es un feminismo muy acomodado y poco vinculado a la mayoría de las mujeres que son mujeres pobres y trabajadoras" (Emiliana, 29 años). Por su parte, algunas interlocutoras cercanas al feminismo radical criticaron, sobre sus pares de agrupaciones socialistas, que en su lucha va "primero la clase que el género" y, sobre el transactivismo, que a veces puede caer en la misoginia (Violeta, 23 años). Así, Feministlán es un campo heterogéneo, cuyo dinamismo responde, al menos en parte, a la competencia simbólica por definir el sentido legítimo de la lucha feminista y las estrategias para llevarla a cabo.

Los señalamientos entre quienes ostentan afinidades políticas distintas son "la expresión simbólica, más o menos trasfigurada, de las relaciones que se establecen en este campo" (Bourdieu y Passeron, 1995, p. 59). Tales relaciones dan cuenta de personas que ocupan posiciones diferentes en Feministlán, en función de sus respectivos volúmenes de capital específico. En este campo, ese capital es el grado de legitimidad con el que se puede usar la categoría "feminista" como un término de autoidentificación. Quienes poseen dicho capital en mayor proporción son quienes ocupan el centro de Feministlán, al tiempo que quienes detentan una cantidad menor son quienes permanecen relegadas en la periferia del campo; al centro y a la periferia de Feministlán les corresponden, respectivamente, mujeres 
"establecidas y marginadas" ${ }^{7}$. En ese sentido, lo que está en juego en Feministlán es la determinación de los criterios que señalan lo que es y lo que no es feminista. Por eso, según Simona (50 años), “...hoy en día hay una compulsión pavorosa sobre lo que es ser feminista y lo que es no ser feminista...".

El grado de legitimidad con el que se puede emplear el término "feminista" es establecido en función de la aplicación del "feministómetro", esto es, una evaluación para determinar el volumen que se posee del capital específico del campo. De dicha aplicación se deriva una práctica de etiquetado que podría parecer meramente descriptiva del fondo de afinidades políticas en Feministlán, pero que, en realidad tiene una función performativa: distribuye, mediante el suministro de etiquetas, a mujeres feministas en posiciones que van del centro a la periferia. En ese sentido, etiquetar es equivalente a asignar (o restar) valor y, a la vez, una forma de condicionar la manera en la que distintos actores se comportan hacia la persona etiquetada (Becker, 2009). Así, "lib-fem", "feminista light", "feminista blanca" o "feminista académica" son categorías empleadas por las "compas" de Garnet (43 años) para indicar su legitimidad menguante, existente, sí, pero no total. Por lo tanto, las etiquetas son pistas que reflejan las relaciones asimétricas de poder en Feministlán. A fin de cuentas, nombrar es un ejercicio de violencia simbólica (Bourdieu y Passeron, 1995) ${ }^{8}$ : quien nombra impone los límites en los que debe ser comprendida la nombrada, su naturaleza, su ser.

El orden jerárquico y las prácticas de etiquetado en Feministlán dejan su huella en la subjetividad de las entrevistadas. Una de esas huellas se manifiesta en la "narrativa del progreso" con la que cuentan sus respectivos pasos por los feminismos. Tal narrativa, al suponer que el proceso de socialización y politización feminista puede dibujarse como una línea recta, considera que hay mujeres "más adelantadas" y, por consiguiente, "más atrasadas" en su proceso de deconstrucción (Lorena, 31 años). Dicho proceso consiste en un ejercicio individual, aunque de base social, para eliminar paulatinamente la influencia cultural machista que se incorporó a nivel del habitus antes de conocer el feminismo. De ahí

\footnotetext{
${ }^{7}$ Este juego de palabras hace referencia a una obra de Elias y Scotson (2016).

${ }^{8}$ La violencia simbólica consiste en "...todo poder que logra imponer significaciones e imponerlas como legítimas disimulando las relaciones de fuerza en que se funda su propia fuerza..." (Bourdieu y Passeron, 1995, p. 44).
} 
el uso constante, entre las entrevistadas, de palabras que muestran los resabios de socializaciones pasadas que cargan consigo mismas como, por ejemplo, "todavía". Hablando de su liberación sexual, Flor (20 años) me dijo que "O sea, diría que sí [aplica el término liberación sexual para describir su biografía] pero al mismo tiempo todavía hay una parte muy conservadora en mí”. Igualmente, Laura (25 años) me contó que, aún después de dos años en el mundo de los feminismos "todavía (...) de repente me encuentro pensando cosas que digo "no ma, eso es súper romántico"”. Ambos casos dan cuenta de una efectividad parcial de las prácticas de socialización y politización feminista, ya que muestran subjetividades que, a pesar de emplear las claves de conocimiento de Feministlán para evaluar su propia “deconstrucción”, siguen siendo influidas por una moral conservadora en cuanto a la sexualidad y el discurso romántico del amor. El "todavía" es una expresión del carácter plural de la socialización de las entrevistadas: los principios de acción contradictorios a los que se han visto expuestas (Lahire, 2004). Además, el "todavía" apunta a la dificultad de desprenderse de la realidad social previamente incorporada, puesto que señala los límites de un manejo volitivo del "yo".

El "adelante" y el "atrás" que componen la narrativa del progreso dan lugar a la distribución desigual de mujeres a lo largo de posiciones que gozan de distinto prestigio dentro de Feministlán": las mujeres "avanzadas" pueden cargar con total legitimidad la categoría "feminista", mientras que las mujeres "atrasadas" no. La hegemonía del primer tipo de mujeres en Feministlán queda claro en cómo sus ejercicios más o menos pasivos de descrédito son aceptados por aquellas a las que van dirigidos: las mujeres "atrasadas", que al mismo tiempo son mujeres “subordinadas". Esto se ve en el diálogo que Lorena (31 años) sostuvo con un par de mujeres que ella considera "más avanzadas" en sus procesos de deconstrucción feminista: “¿Y por qué no nos llevábamos bien antes?’ [les preguntó Lorena]. Y me dicen 'pues porque estabas bien tonta'. Y yo, 'ay, perdón”'. Con esto no quiero decir que todas las mujeres que ocupan la periferia acepten su condición subordinada, ya que, como dice Garnet (43 años), la dinámica de Feministlán es de "luchas internas”. De hecho,

\footnotetext{
${ }^{9}$ La distinción "adelante" y "atrás" tiene una expresión observable en las manifestaciones feministas de la Ciudad de México. Al margen de la familia de las víctimas, primero van las agrupaciones separatistas y radicales, después los contingentes mixtos y al final algunos hombres. Así, en estas marchas se replica el orden jerárquico de Feministlán.
} 
el coro de voces que habita la periferia de Feministlán da cuenta de niveles distintos de subordinación y antagonismo con el centro del campo.

\section{Amor y sexualidad}

El amor y la sexualidad son elementos clave para determinar la posición de una mujer al interior de Feministlán, ya que constituyen ámbitos de experiencia para demostrar el nivel de congruencia con los principios políticos que se fueron adquiriendo a lo largo del proceso de socialización y politización feminista. Por eso, el amor y la sexualidad son tomados como ámbitos para poner en acto (hacer un performance) la identidad política ${ }^{10}$.Y es a partir de las características de ese performance que, entonces, se pondera el nivel de legitimidad con el que una mujer porta la categoría "feminista" para definirse a sí misma. Esto significa que, como ocurría en la Europa de los siglos XVII, XVIII y XIX ${ }^{11}$, el amor y la sexualidad son una cuestión de interés público, dado que es en virtud de la manera en que se practican que, en parte, las relaciones sociales de Feministlán adoptan su organización interna.

En el orden simbólico de Feministlán, no todas las formas de amar y de ejercitar el deseo sexual gozan del mismo valor. Las relaciones amorosas que operan bajo acuerdos heterosexuales son, en general, representadas con una carga negativa. Esto es cierto incluso en el caso de aquellas mujeres que se definen como heterosexuales. Por ejemplo, Sabina (27 años) me dijo que la heterosexualidad, aun cuando sea "liberada", implica dominio masculino, en tanto que "una mujer no puede coger con un hombre si el hombre no tiene una erección”. A su vez, Violeta (23 años) me contó que ser una mujer heterosexual no sólo implica una contradicción con los principios políticos del feminismo, sino también algo que ella asocia con quienes "nos aferramos así a la heteronorma...". Entonces, las relaciones amorosas de corte heterosexual parecen obtener un puntaje muy bajo en el feministómetro y,

\footnotetext{
${ }^{10} \mathrm{El}$ amor y la sexualidad no son los únicos ámbitos por los que se puede expresar y ponderar la legitimidad como mujer feminista. Otro igualmente importante, pero que no trabajo en este artículo, es la detención de capital cultural feminista.

${ }^{11}$ Dice Eva Illouz que las pautas de emparejamiento en la Europa premoderna (lo que ella inscribe entre los siglos XVII y XIX) tenían un interés público, dado que en cada matrimonio se ponía en juego el prestigio y las riquezas familiares (2012). Por eso, el problema de los hombres y mujeres de aquella época era "encontrar a alguien con un valor que coincidiera con el propio (Illouz, 2012, p. 115).
} 
por lo mismo, un lugar asegurado en la periferia de Feministlán. A fin de cuentas, tales relaciones únicamente permiten comunicar que sus involucradas poseen un volumen bajo del capital específico del campo.

Las representaciones de la heterosexualidad antes mencionadas nutren una serie de prácticas que dan cuenta del ordenamiento desigual de posiciones dentro de Feministlán. Esto puede verse en los casos de Violeta (23 años) y Laura (25 años), puesto que, en el contexto de sus colectivas, sus respectivas historias amorosas eran, justo por ser heterosexuales, de importancia menor en comparación con las de sus pares lesbianas o en vías de serlo. Por eso, según Violeta: “...a veces sí, desde la heterosexualidad, en esos espacios como que no quieres hablar mucho de tus experiencias sentimentales". De manera similar, Laura me contó que, al momento de compartir sus problemas de pareja, se sintió muy juzgada por una de sus amigas feministas que se "alesbianó”: “...yo llego a contarle mis traumas con J y ella era como de 'güey, pues es vato'. ¿Sabes? Era como 'ya no me cuentes de eso'. Yo como 'ok, ya no te puedo contar, porque soy...'. Como que empieza una onda muy de juzgar a las otras".

Ambos casos revelan un par de cosas. Por un lado, que hay un orden jerárquico de problemas amorosos que encuentran su calca o correlato en la distribución desigual de mujeres en virtud de su deseo sexual y formas de establecer relaciones amorosas. Por otro lado, que el trabajo emocional de apoyo en las colectivas puede llegar a distribuirse en función de la legitimidad feminista que se manifiesta mediante del deseo sexual y el modelo amoroso que siguen sus integrantes. En ese sentido, el orden simbólico de Feministlán puede tener consecuencias prácticas como la autocensura y la distribución selectiva del trabajo emocional, dos manifestaciones de las relaciones asimétricas de poder que estructuran las dinámicas del campo.

Tanto las prácticas como las representaciones anteriores pueden derivar en la conversión de Feministlán en un régimen feminista del amor y el deseo sexual, esto es, un espacio donde circulan normas acerca de las formas correctas de sentir y expresar lo sentido (López, 2013). No sólo se trata de un régimen porque en él se colocan en posiciones de jerarquía diferente a 
quienes sostienen relaciones amorosas y deseos distintos, sino, también, porque se busca disciplinar a sus integrantes para que mantengan un posicionamiento congruente, a nivel de las acciones, pensamientos y emociones, con los principios feministas de una colectiva o corriente del feminismo. Por ejemplo, Lorena (31 años) me contó que las mujeres lesbianas de la agrupación feminista en la que participa se sintieron decepcionadas después de contarles que no era lesbiana y que comenzaba a salir con un hombre al que recién había conocido. Una de sus compañeras le dijo: “...quedaste que te ibas a acercar a esto [relacionarte sexoafectivamente con mujeres] y no es que estés regresando, sino que no te veo avanzar como prometiste que avanzarías". Esta llamada de atención es el "recordatorio"12 de una "regla del sentir" (Hochschild, 2012), ya que, al señalar el error de Lorena, devela la regla misma: avanzar en el proceso de deconstrucción es establecer, en el terreno del amor y la sexualidad, relaciones con mujeres. Además, la llamada de atención funciona como un "dispositivo emocional" (López, 2011) que busca reconducir las formas de actuar, pensar y sentir de la infractora al terreno de lo permitido; esto lo logra comunicando la decepción de quienes gozan de mayor estima colectiva, generando culpa en la persona a la que va dirigida y señalando qué personas sí pueden ser objeto de amor y de deseo sexual. Por eso, en la llamada de atención se ve al elenco de socialización y politización feminista enseñando cómo ser una mujer feminista.

El punto de expresión más claro del régimen feminista de la sexualidad y el amor se condensa en la palabra "heteroinfiltrada", pues ese término carga consigo las connotaciones de desprestigio y destino subalterno que se le confiere a quienes, en virtud de ser heterosexuales y establecer relaciones amorosas con hombres, habitan en la periferia de Feministlán. Heteroinfiltrada es quien comparte el conocimiento feminista con "machos que sólo buscan burlarse de las mujeres"; alguien que, a pesar de ser feminista y pretender romper con los hombres, continúa brindándoles "servicios" en el amor (Ruth, 33 años). Por lo tanto es una suerte de traidora que aprovecha su condición de género para escabullirse por los intersticios de un dominio al que no pertenece. Esto me regresa a la función performativa de las prácticas de etiquetado. Llamar heteroinfiltrada a alguien no es una forma de denominar lo que se

\footnotetext{
12 Para Hochschild, los recordatorios de reglas del sentir se pueden reconocer en la forma en la que otras personas evalúan y sancionan nuestras emociones (2012).
} 
encuentra en dicha persona, sino de atribuírselo ${ }^{13}$. Tal atribución es realizada por quien puede nombrarse y ser reconocida como defensora legítima de los códigos de valor que operan dentro del régimen feminista del amor y la sexualidad: una "emprendedora moral"14 que salvaguarda, mediante llamadas de atención que sancionan simbólica y emocionalmente, el conjunto de normas que, se supone, todas deberían acatar.

Un aspecto sobresaliente de las llamadas de atención es que éstas son aceptadas por las personas a las que van dirigidas. Dicha aceptación es lo que hace del régimen una hegemonía, es decir, un estado de cosas en el que el mandato de quienes están a la cabeza es asumido, aunque no siempre bien apreciado, por quienes ocupan las posiciones subalternas. De ahí que, parafraseando a Raewyn Connell, las mujeres "establecidas" de Feministlán tengan éxito al reclamar "su derecho a ejercer la autoridad" (2019, p. 113). Esto puede verse cuando las interlocutoras callan en lugar de impugnar el sitio de segunda importancia al que son relegados sus trajines amorosos (Laura, 25 años; Violeta, 23 años); cuando piden "perdón" por no llevar un proceso "avanzado" de deconstrucción feminista (Lorena, 31 años); cuando, en razón de considerar que existe una contradicción entre ser feminista y tener un deseo heterosexual, justifican las críticas que les hacen sus compañeras lesbianas o en vías de serlo (Violeta, 23 años); cuando reconocen la autoridad política e intelectual de quien se inviste como protectora de las leyes de Feministlán (Ruth, 33 años).

El respeto a las reglas del campo, así como el reconocimiento de la autoridad de quienes se encargan de movilizarlas, es lo que garantiza la reproducción del orden jerárquico de Feministlán. En otras palabras: al usar y validar las reglas, el centro y la periferia certifican los criterios que las lleva a ocupar sus respectivas posiciones dentro del campo y, por lo tanto, a gozar de volúmenes distintos de capital simbólico. La buena estima que se le tiene a las reglas no se debe a su valor intrínseco, sino al hecho de que son impulsadas por quienes gozan del mayor volumen del capital específico de Feministlán: las mujeres que ostentan con

\footnotetext{
${ }^{13}$ Esto quiere decir que un acto es independiente de su etiqueta: "Si nadie definió esa acción como desviada, entonces no puede, por definición, ser desviada" (Becker, 2009, p. 204).

${ }^{14}$ El término "emprendedora moral" es original de Howard Becker, quien lo usa para referirse a las personas que, en la defensa de un orden, llevan a cabo un etiquetado de aquellos o aquellas que cometen acciones "desviadas" (2009).
} 
mayor legitimidad la categoría "feminista". Esto equivale a decir que la legitimidad de las reglas descansa sobre una relación de poder asimétrica entre el centro y la periferia (Bourdieu y Passeron, 1995). Ignorar lo anterior, cuestión que suele ocurrir en virtud del deseo de acoplamiento a las reglas del campo, es lo que lleva a tomar las reglas como si fueran válidas en sí mismas (Bourdieu y Passeron, 1995).

\section{¿La (feminista) perfecta?}

Lo dicho hasta aquí me permite trazar un paralelismo con "la perfecta" de Angela McRobbie. "La perfecta" es un ideal de género que circula en distintas redes sociales, libros, guías y manuales de autoayuda. Su llamado al mejoramiento personal es incorporado por adolescentes y mujeres jóvenes como una "tecnología del yo", cuya lógica puede verse en los ejercicios de autoevaluación que practican distintas mujeres para, entonces, calcular la distancia que media entre sus respectivas vidas y el ideal de la mujer perfecta. De ahí que, según McRobbie, dichas mujeres terminen fiscalizándose a sí mismas: “QQué tan bien lo hice hoy? ¿Logré comer menos calorías? ¿Comí más saludable? ¿Fui al gimnasio?” (2015, p. 9).

La "feminista perfecta" 15 es una representación ideal de género que concentra las características que se contraponen a la figura de la heteroinfiltrada y al resto de categorías referidas por las entrevistadas con las que se denomina a las feministas que obtienen un bajo puntaje en el feministómetro: "feministas blancas", "feministas académicas" y "feministas light". De acuerdo con los relatos de las entrevistadas, la feminista perfecta es lesbiana o está en proceso de serlo, tiene una relación poliamorosa, milita en una colectiva que es sensible al feminismo radical, no colabora con el Estado, sino que lo combate, y privilegia el aprendizaje práctico del feminismo por encima del teórico. Las mujeres que logran acercarse a esta representación son las que pueden reclamar, con legitimidad, lo que está en juego en Feministlán: la capacidad de autodenominarse "feminista". Quien más se acerque al ideal, mayor legitimidad tendrá al interior de Feministlán y, por lo tanto, ocupará una posición alejada del circuito en el que habitan, con aceptación o resignación, las personas de

\footnotetext{
${ }^{15} \mathrm{La}$ "feminista perfecta" no es una figura realmente existente. Se trata de un "tipo ideal" que yo construí en oposición a los rasgos que detentan las personas marginadas en Feministlán.
} 
legitimidad dudosa. Lo anterior me permite decir que, en este caso, el género puede ser entendido como un capital. Así como sucede con un capital en un campo (Bourdieu, 2001), la acumulación de características que componen la representación ideal de la mujer feminista perfecta determina la posición dentro de Feministlán. Tal acumulación de características es, como el capital, la acumulación de trabajo incorporado (Bourdieu, 2001), a lo largo de la deconstrucción llevada a cabo durante el proceso de socialización y politización feminista. En ese sentido, el género es un criterio estructurante de Feministlán.

Como en el caso de la perfecta de McRobbie, la feminista perfecta también supone una "tecnología del yo". Dicha tecnología recoge los aprendizajes mediatizados por el elenco de socialización y politización feminista y los adopta como referentes de evaluación personal. Cuando una no logra estar a la altura de la representación ideal de la feminista perfecta, precisamente porque su forma de establecer relaciones de pareja y su deseo sexual no se ajustan a la norma de Feministlán, entonces sobreviene un sentimiento de culpa y una acción de reproche:

Hubo un momento en el cual si eras feminista era porque creías en el amor libre y no había de otra. Si tenías una relación monogámica, era como "no amiga, eso no es feminista”. Entonces como que muchas de nosotras nos sentíamos muy incómodas... porque yo decía "es que no me siento tan segura de mí misma como para tener una relación abierta, pero como eso es feminista... yo voy a ser así" (Laura, 25 años).

Este pasaje muestra cómo la falta de interés por tener relaciones abiertas, lejos de ser una decisión que emana y se justifica a través de una consulta de los propios deseos, constituye una falla individual: "no me siento tan segura de mí misma" (Laura, 25 años). Aquí vemos cómo se borra la vocación sociológica ${ }^{16}$ que distingue a la crítica de las interlocutoras hacia el amor romántico, puesto que su desajuste con la representación ideal de la "feminista

\footnotetext{
${ }^{16}$ La crítica sociológica de las entrevistadas consiste en un análisis que no culmina en el reproche y la culpabilización personal, porque, al dirigir su mirada hacia las condiciones sociales que habilitan la emergencia y reproducción del amor romántico, no encuentra en las personas la fuente de los malestares vividos en las relaciones de pareja (Illouz, 2012).
} 
perfecta" no es producto, según Laura, de relaciones asimétricas de poder o de instituciones sociales, sino de defectos individuales: inseguridades.

Antes de finalizar, cabe dibujar algunos matices. El orden simbólico que señala a las parejas amorosas heterosexuales como carentes de valor feminista es paralelo a representaciones contrarias. Así, Ruth (33 años) recibió una invitación por parte de una compañera lesbofeminista de su escuela para que deje a su pareja varón y comience una familia homoparental con otra mujer y, a la vez, ha sido respetada y bienvenida sin necesidad de enseñar credenciales de ningún tipo de deseo sexual que avale su legitimidad como feminista. De hecho, Ruth me contó que otra de las entrevistadas la invitó a formar parte de una agrupación, dejándole bien claro que no por ser heterosexual tenía impedido ser feminista: "Simona es bien chida en eso, porque Simona no es como otras feministas de que 'no, si no eres lesbiana, no me hables, aléjate"'. No obstante, la invitación de Simona (50 años) implica el reconocimiento de las normas que vuelven problemático, al interior de Feministlán, el deseo heterosexual de una mujer feminista, puesto que, de lo contrario, su aclaración (no tienes que ser lesbiana para ser feminista) no tendría sentido. Éste es un caso de aquello que Bourdieu denominó "revoluciones parciales", en las cuales, si bien se puede optar por rutas alternas a las sugeridas por las normas del campo, no se ponen "en tela de juicio los fundamentos mismos del juego..." (2002, p. 122).

Lo anterior es una muestra de que la actual hegemonía en Feministlán no está libre de momentos de tensión. A cada uno de los silencios frente a la autoridad de las normas que gobiernan el amor y el deseo sexual en Feministlán, le corresponden voces disidentes: "Qué perro miedo me dan estas morras que desde la teoría nos quieren venir a explicar cómo conducir nuestra intimidad. Que si falta deconstrucción por aquí o por allá. Yo no me volví feminista para rendirle cuentas a ningún tribunal" (Lucrecia, 23 años). Las palabras de Lucrecia pueden verse como una estrategia revolucionaria dentro de Feministlán, cuya finalidad es cuestionar la validez de los criterios con los que, desde el centro del campo, se determina si algo es o no es feminista. De ahí que no sea exagerado decir que al interior de Feministlán pueden ocurrir acciones contrahegemónicas que pretendan, como dice Bourdieu, "romper los cerrojos de derecho de entrada" (2020, p. 120). 
No todas las mujeres feministas son igualmente susceptibles de ser juzgadas bajo los parámetros del feministómetro $\mathrm{y}$, por lo tanto, no todas esas mujeres sienten de la misma manera la presión de ser ubicadas en una u otra posición de Feministlán. Las mujeres que claramente están bajo el radar del feministómetro son aquellas que: a) mantienen vínculos con un elenco de socialización y politización feminista orientado hacia el feminismo radical, mas no por ello se identifican como feministas radicales; b) participan frecuentemente en los espacios donde se llevan a cabo las discusiones del activismo y militancia feminista. En ese sentido, la proximidad con el elenco de socialización y politización feminista, más que el hecho mismo de establecer relaciones amorosas heterosexuales, es lo que coloca a una persona dentro de la jurisdicción de quienes, empleando los términos de Lucrecia, constituyen el "tribunal" feminista y que, en mi propia nomenclatura, corresponden a las que habitan el centro de Feministlán. Sentir el fuego del feministómetro depende del capital social detentado.

Las feministas que sienten tenuemente el fuego de la fiscalización ejercida por el feministómetro se dividen en dos grupos. El primero se trata de mujeres que: a) no conviven demasiado en los espacios de interacción feminista; b) ejercen el activismo de manera esporádica; c) participan en agrupaciones sin vínculos fuertes con el feminismo radical. El segundo grupo se compone de mujeres que, aun cuando participaron en agrupaciones feministas, hoy se encuentran alejadas del activismo y la militancia. Lo que distingue a estas mujeres es que son las únicas que no creen que valga la pena luchar por aquello que está en juego dentro de Feministlán, dado que, para ellas, ser feminista es una cuestión independiente a la validación otorgada por quienes ocupan el centro del campo. El precio que pagan estas mujeres por su autonomía es la marginación: no toman parte en las discusiones sobre agendas ni estrategias.

\section{Reflexiones finales}

Lo anterior me permite entender Feministlán como un orden de género: la distribución de personas en posiciones de prestigio social diferente en virtud de sus muestras de feminidad da cuenta de relaciones asimétricas de poder entre mujeres. La finalidad de este orden es un 
"proyecto de género" que consiste en eliminar (Connell, 2019, p.107), mediante el disciplinamiento llevado a cabo por las emprendedoras morales que habitan su centro (Becker, 2009), las contradicciones entre los principios de socialización feministas y no feministas que tienen sus habitantes.

Feministlán también adquiere el perfil de un régimen emocional (López, 2013); ello se debe a que sus reglas del sentir son movilizadas por emprendedoras morales para disciplinar al resto de sus integrantes. De dicho disciplinamiento se espera que las habitantes de Feministlán se ciñan a las formas pretendidamente correctas de sentir y expresar lo sentido en el terreno del amor y la sexualidad (Hochshild, 2012). Se trata de incidir en la práctica de las entrevistadas para que éstas "hagan género" de manera disidente en sus respectivas relaciones amorosas y sexuales.

Por otro lado, Feministlán puede ser visto como un campo. El capital específico de Feministlán es la determinación de qué feminidad sí es y cuál no es feminista, lo cual se establece mediante la evaluación de las formas de hacer género en el amor y la sexualidad. Quienes dan muestras de una feminidad cercana a la representación ideal de la "feminista perfecta" son quienes habitan el centro del campo, mientras que quienes no lo hacen permanecen, desde la aceptación o la confrontación, en la periferia. La defensa de dicha distribución, estrategia adoptada por quienes ocupan el centro del campo (Bourdieu, 2002), es la defensa de un tipo particular de mujer: aquel que está encarnado en la feminista perfecta.

Ahora bien, la organización interna de Feministlán no sólo se lleva a cabo en función de la forma de hacer género en el amor y la sexualidad de sus habitantes. Otro factor sumamente importante, según mi investigación, es la clase social. Las etiquetas "feminista blanca" y "feminista académica" se emplean para denominar a personas que habitan en la periferia de Feministlán, pero que, fuera de este campo específico, acumulan una serie de privilegios asociados a las clases dominantes. Por consiguiente, en el campo aquí revisado se presenta una paradoja: entre más privilegios de clase se acumulan fuera de Feministlán, menos legitimidad, como persona feminista, se tiene en Feministlán. Abundar sobre esta cuestión es una deuda por saldar en futuras investigaciones. 
La lucha al interior de Feministlán es lo que le da su dinamismo, pues dentro de cada impugnación a su orden descansa un potencial trasformador. Tales impugnaciones se distribuyen a lo largo de un continuum de acciones, que van desde las menos (resistencias) a las más frontales (antagonismos) (Modonesi, 2016). Las resistencias se expresan como intentos por cambiar la narrativa del progreso que divide a "avanzadas" de "retrasadas" (Violeta, 23 años) o como renuncia a la ponderación de quién sí merece el título "mujer feminista" (Juana, 37 años), mientras que los antagonismos implican cuestionamientos, críticas y deliberación (Lucrecia, 23 años). De cualquier forma, el estado actual de Feministlán (entendido como un campo, un orden de género y un régimen emocional) muy probablemente se trasforme: otros serán los elementos en juego, otras serán las personas legítimas e ilegítimas.

\section{Agradecimientos}

Quiero agradecer a las doctoras Ana Paulina Gutiérrez Martínez, Karine Tinat y Natalia Tenorio Tovar por sus valiosos comentarios y sugerencias en la preparación de este texto. Igualmente, agradezco a cada una de las mujeres que entrevisté, puesto que este artículo es, en buena medida, producto de su generosidad.

\section{Referencias bibliográficas}

Backus, Faedra y Mahalik, James. (2011). The Masculinity of Mr. Right: Feminist Identity and Heterosexual Women's Ideal Romantic Partners. Psychology of Women Quarterly, 35(2), 318-326. doi: https://doi.org/10.1177/0361684310392357

Becker, Howard. (2009). Outsiders. Hacia una sociología de la desviación. Buenos Aires: Siglo XXI. 
Berger, Peter y Luckmann, Thomas. (2012). La construcción social de la realidad. Buenos Aires: Amorrortu.

Bertaux, Daniel. (2005). Los relatos de vida. Perspectiva etnosociológica. Barcelona: Edicions Bellaterra.

Blázquez, Norma. (2010). Epistemología feminista: temas actuales. En Norma Blázquez, Fátima Flores y Maribel Ríos (Coords.), Investigación feminista. Epistemología, metodología y representaciones sociales (pp. 21-38). México: Centro de Investigaciones Interdisciplinarias en Ciencias y Humanidades, UNAM.

Bourdieu, Pierre. (2003). El oficio de cientifico. Ciencia de la ciencia y reflexividad. Curso del Collége de France 2000-2001. Barcelona: Anagrama.

Bourdieu, Pierre. (2002). Campo de poder, campo intelectual. Tucumán: Editorial Montressor.

Bourdieu, Pierre. (2001). Poder, derecho y clases sociales. Bilbao: Desclée de Brouwer.

Bourdieu, Pierre y Passeron, Jean-Claude. (1995). La reproducción. Elementos para una teoría del sistema de enseñanza. México: Fontamara.

Butler, Judith. (2009). Performatividad, Precariedad y Políticas Sexuales. AIBR. Revista de Antropología Iberoamericana, 4(3), 321-336. doi: https://doi.org/10.11156/78

Butler, Judith. (2007). El género en disputa. El feminismo y la subversión de la identidad. Barcelona: Paidós.

Cabral, Mauro. (2009). Interdicciones. Escrituras de la intersexualidad en castellano. Córdoba: Anarrés Editorial. 
Connell, Raewyn. (2019). Masculinidades. México: CIEG, UNAM.

Elias, Norbert y Scotson, John. (2016). Establecidos y Marginados. Una investigación sociológica sobre problemas comunitarios. México: Fondo de Cultura Económica.

Esteban, Mari Luz. (2009). Identidades de género, feminismo, sexualidad y amor: Los cuerpos como agentes. Política y Sociedad, 46(1-2), 27-41. Recuperado de https://revistas.ucm.es/index.php/POSO/article/view/POSO0909130027A

Esteban, Mari Luz. y Távora, Ana. (2008). El amor romántico y la subordinación social de las mujeres: Revisiones y propuesta. Anuario de Psicología, 39(1), 59-73. Recuperado de https://www.raco.cat/index.php/AnuarioPsicologia/article/view/99354/159761

Faulkner, Sandra y Ruby, Paul. (2015). Feminist Identity in Romantic Relationships: A Relational Dialectics Analysis of E-mail Discourse as Collaborative Found Poetry. Women's Studies in Communication, 30(2), 206-226. doi: https://doi.org/10.1080/07491409.2015.1025460

Ferrarotti, Franco. (2007). Las historias de vida como método. Convergencia. Revista de Ciencias sociales, 14(44), 15-40. Recuperado de https://convergencia.uaemex.mx/article/view/1365

García, Nagore. (2017). Love and its Contradictions: Feminist Women's Resistance Narratives in their Love Narratives. Journal of Popular Romance Studies, (6), 1-19. Recuperado de https://www.jprstudies.org/2017/04/love-and-its-contradictionsfeminist-womens-resistance-strategies-in-their-love-narrativesby-nagore-garciafernandez/

Hand, Tammy. (2013). Gender and power relations and feminism in young heterosexual women's lives (Tesis de doctorado en Psicología). Universidad del Sur de Australia, 


Sur de $\quad$ Australia.
a.alma.exlibrisgroup.com/view/delivery/61USOUTHAUS

Harding, Sandra. (1998). ¿Existe un método feminista? En Eli Bartra (Comp.), Debates en torno a una metodología feminista (pp. 9-34). México: Universidad Autónoma Metropolitana.

Hochschild, Arlie. (2012). The managed heart. Commercialization of Human Feeling. California: University of California Press.

Hochschild, Arlie. (1979). Emotion Work, Feeling Rules, and Social Structure. The American Journal of Sociology, 85(3), 551-575. doi: https://doi.org/10.1086/227049

Illouz, Eva. (2012). ¿Por qué duele el amor? Una explicación sociológica. Madrid: Katz Editores.

Kahn, Robert y Canell, Charles. (1977). Entrevista. Investigación Social. En David Sills (Comp.), Enciclopedia Internacional de las Ciencias Sociales (pp. 266-276). Madrid: Aguilar.

Lahire, Bernard. (2004). El hombre plural. Los resortes de la acción. Barcelona: Edicions Bellaterra.

López, Oliva. (2013). La pertinencia de una historia de la construcción emocional del cuerpo femenino en México entre 1850-1910. Abordaje desde el construccionismo social. Revista Latinoamericana de Estudios sobre Cuerpos, Emociones y Sociedad, 5(12), 51-64. Recuperado de http://relaces.com.ar/index.php/relaces/article/view/359/353. 
López, Oliva. (2011). Introducción: El lugar de las emociones en el mundo racional. En Oliva López (Coord.), La pérdida del paraíso. El lugar de las emociones en la sociedad mexicana entre los siglos XIX y XX(pp. 1-19). México: UNAM, FES Iztacala.

McRobbie, Angela. (2015). Notes on the Perfect. Competitive Femininity in Neoliberal Times. Australian Feminist Studies, 3(83), 3-20. doi: https://doi.org/10.1080/08164649.2015.1011485

Modonesi, Massimo. (2016). El principio antagonista. Marxismo y acción política. México: Ítaca.

Payne, Robin Kay-Marie. (2010). Love and liberation: Second-wave feminisms and the problem of romantic love (Tesis de doctorado en Historia). Universidad de Carolina del Norte, Carolina del Norte. doi: https://doi.org/10.17615/b0gd-gb69

Pinckert, Miranda. (2012). The private face of feminism: A grounded theory of how feminist identification impacts heterosexual romantic relationships (Tesis de doctorado en Psicología Clínica). Universidad de Sofía, California. Recuperado de https://search.proquest.com/openview/c6bfee20ce38fca332ac6468596e1c69/1.pdf?c $\underline{\mathrm{bl}=18750 \& \text { diss }=\mathrm{y} \& \text { pq-origsite }=\text { gscholar. }}$.

Pons, Alba y Garosi, Eleonora. (2016). Trans. En Hortensia Moreno y Eva Alcántara (Coords.), Conceptos clave en los estudios de género (pp. 307-325). México: UNAM, Programa Universitario de Estudios de Género.

Rojas, Martha Luz. (2013). Lo biográfico en sociología. En María Luisa Tarrés (Coord.), Observar, escuchar y comprender. Sobre la tradición cualitativa en la investigación social (pp. 159-183). México: El Colegio de México, FLACSO

Rudman, Laurie y Phelan, Julie. (2007). The Interpersonal Power of Feminism: Is Feminism Good for Romantic Relationships? Sex Roles, 57(11-12), 787-799. doi: https://doi.org/10.1007/s11199-007-9319-9 
Scott, Joan. (2008). El género: una categoría útil para el análisis histórico. En Joan Scott, Género e historia (pp. 48-74). México: Fondo de Cultura Económica.

Vela, Fortino. (2013). Un acto metodológico básico de la investigación social: la entrevista cualitativa. En María Luisa Tarrés (Coord.), Observar, escuchar y comprender. Sobre la tradición cualitativa en la investigación social (pp. 63-88). México: El Colegio de México, FLACSO.

West, Candace y Zimmerman, Don. (1987). Doing Gender. Gender and Society, 1(2), 125151. Recuperado

de https://www.gla.ac.uk/0t4/crcees/files/summerschool/readings/WestZimmerman_19 87 DoingGender.pdf

Yoder, Janice; Perry, Rachel y Saal, Ellen. (2007). What Good is a Feminist Identity?: Women's Feminist Identification and Role Expectations for Intimate and Sexual Relationships. Sex Roles, 45(5-6), 365-372. doi: https://doi.org/10.1007/s11199-0079269-2

\section{SOBRE EL AUTOR}

Alonso Pi Cholula es licenciado en Sociología por la Universidad Nacional Autónoma de México y maestro en Estudios de Género por El Colegio de México. Además, ha realizado estudios de intercambio en la Universitat Pompeu Fabra. Sus principales líneas de investigación incluyen: género, cuerpo, emociones y subjetividades. 